\title{
miR-130b regulates PTEN to activate the PI3K/Akt signaling pathway and attenuate oxidative stress-induced injury in diabetic encephalopathy
}

\author{
YONGHUA LEI ${ }^{1}$, MING YANG ${ }^{1}$, HONG $\mathrm{LI}^{2}$, RONGJUAN XU² ${ }^{2}$ and JUNBAO LIU ${ }^{1}$ \\ ${ }^{1}$ Department of Traditional Chinese Medicine, Henan Provincial People's Hospital, Zhengzhou University People's Hospital, \\ Henan University People's Hospital, Zhengzhou, Henan 450003; ${ }^{2}$ Department of Endocrinology, \\ Longhua Hospital Shanghai University of Traditional Chinese Medicine, Shanghai 200032, P.R. China
}

Received September 14, 2020; Accepted April 29, 2021

DOI: $10.3892 /$ ijmm.2021.4974

\begin{abstract}
Diabetic encephalopathy (DE) is one of the main chronic complications of diabetes, and is characterized by cognitive defects. MicroRNAs (miRNAs/miRs) are widely involved in the development of diabetes-related complications. The present study evaluated the role of miR-130b in $\mathrm{DE}$ and investigated its mechanisms of action. PC12 cells and hippocampal cells were exposed to a high glucose environment to induce cell injuries to mimic the in vitro model of DE. Cells were transfected with miR-130b mimic, miR-130b inhibitor and small interfering RNA (si)-phosphatase and tensin homolog (PTEN) to evaluate the protective effect of the miR-130b/PTEN axis against oxidative stress in high glucose-stimulated cells involving Akt activity. Furthermore, the effect of agomir-130b was also assessed on rats with DE. The expression of miR-130b was reduced in the DE models in vivo and in vitro. The administration of miR-130b mimic increased the viability of high glucose-stimulated cells, prevented apoptosis, increased the activity of superoxide dismutase (SOD), decreased the malondialdehyde (MDA) content, activated Akt protein levels and inhibited the mitochondria-mediated apoptotic pathway. The administration of miR-130b inhibitor exerted opposite effects, while si-PTEN reversed the effects of miR-130b inhibitor. In vivo, the administration of agomir-130b attenuated cognitive disorders and neuronal damage, increased SOD activity, reduced the MDA content, activated Akt protein levels and inhibited the mitochondria-mediated apoptosis pathway in rats with $\mathrm{DE}$. On the whole, these results suggest that miR-130b activates the PI3K/Akt signaling pathway to
\end{abstract}

Correspondence to: Dr Junbao Liu, Department of Traditional Chinese Medicine, Henan Provincial People's Hospital, Zhengzhou University People's Hospital, Henan University People's Hospital, 7 Weiwu Road, Zhengzhou, Henan 450003, P.R. China

E-mail: zhongyi450003@163.com

Key words: diabetic encephalopathy, microRNA-130b, phosphatase and tensin homolog, rat, oxidative stress exert protective effects against oxidative stress injury via the regulation of $\mathrm{PTEN}$ in rats with $\mathrm{DE}$.

\section{Introduction}

Diabetic encephalopathy (DE) is one of the main chronic complications of diabetes, and is characterized by acquired cognitive and behavioral defects, accompanied by changes in brain morphology and abnormal neurophysiological functions (1-3). The clinical manifestations of DE include decreased learning and memory ability, impaired comprehension and judgment, and slow thinking $(4,5)$. It is of great importance to determine the pathogenesis of DE and to identify effective preventive and treatment strategies.

MicroRNAs (miRNAs/miRs) are a group of short non-coding RNAs composed of 20-22 nucleotides, which play a key role in mRNA suppression and degradation (6). Previous studies have demonstaated that miRNAs are widely involved in the development of diabetes-related complications (7-10). miR-130b is downregulated in the serum of patients with diabetic nephropathy (DN), and has been reported to improve epithelial-interstitial transition in DN and ameliorate tubulointerstitial fibrosis $(11,12)$. The expression of $\mathrm{miR}-130 \mathrm{~b}$ is decreased in the serum of patients with diabetes with coronary heart disease complications (13). However, the expression pattern and role of miR-130b in DE is currently unknown.

Previous studies have indicated that phosphatase and tensin homolog (PTEN) is one of the target genes of miR-130b (14-16). PTEN is an antioncogene involved in the regulation of cell proliferation, migration, differentiation and invasion in various malignant tumor cells (17). PTEN exerts its biological function in part by inhibiting the PI3K/Akt signaling pathway (18). The PI3K/Akt signaling pathway is a key signaling pathway involved in cell metabolism, growth, proliferation, survival, transcription and protein synthesis (19). In addition, the PI3K/Akt signaling pathway has also been shown to be associated with oxidative stress (20-22), which has been regarded as one of the pathogenesis of DE (23). Thus, the present study aimed to evaluate whether miR-130b activates Akt activity to protect against oxidative stress-induced injury via the regulation of PTEN in DE. 


\section{Materials and methods}

Cell culture and high glucose treatment. PC12 (no. CL-0480) and hippocampal cells (no. CP-R107) were obtained from Procell Life Science \& Technology Co., Ltd. PC12 and hippocampal cells were cultured in RPMI-1640 medium (Gibco; Thermo Fisher Scientific, Inc.) containing $11.11 \mathrm{mM}$ glucose (Sigma-Aldrich LLC.), $15 \%$ fetal bovine serum (Gibco; Thermo Fisher Scientific, Inc.) and 1\% penicillin-streptomycin (Gibco; Thermo Fisher Scientific, Inc.), and placed in a cell incubator at $37^{\circ} \mathrm{C}$ with $5 \% \mathrm{CO}_{2}$. For high glucose conditions, cells were cultured in the aforementioned medium but containing $75 \mathrm{mM}$ glucose for $72 \mathrm{~h}(24)$.

Animals and treatment. Male Wistar rats $(\mathrm{n}=40$; weight, 180-220 g) were purchased from Chengdu Dashuo Experimental Animal Co., Ltd. Following one week of adaptive feeding, the rats were randomly divided into four groups ( $\mathrm{n}=10$ /group) and kept in their cages in a controlled environment, at constant room temperature $\left(18-25^{\circ} \mathrm{C}\right)$ and humidity (40-60\%) under a normal 12-h light/dark cycle. Rats in the control group received an intraperitoneal injection of $0.9 \%$ saline. Rats in the other groups were administered streptozotocin (STZ; Sigma-Aldrich; Merck KGaA) in a single intraperitoneal injection at a dose of $60 \mathrm{mg} / \mathrm{kg}$ for the induction of diabetes. At $72 \mathrm{~h}$ after the STZ injection, $200 \mu \mathrm{l}$ blood were collected from the tail vein to measure blood glucose, and blood glucose levels $\geq 16.7 \mathrm{mmol} / 1$ were considered to indicate successful modeling. The STZ-treated rats were divided into three groups at three days after the STZ injection. The model group was left untreated and served as the untreated diabetic group. The agomir-NC and agomir-130b groups received agomir-NC (miR4N0000001-4-5; Guangzhou RiboBio Co., Ltd.) or agomir-130b (miR40000837-4-5; Guangzhou RiboBio Co., Ltd.) via intranasal administration once a week at a dose of $5 \mathrm{nmol}(25)$. These treatments were continued until the end of the study period ( 8 weeks). The study protocol was approved by the Animal Experimental Ethics Committee of Henan Provincial People's Hospital (approval no. 2020408A).

Preparation of hippocampal samples. Following an intraperitoneal injection of $3 \%$ pentobarbital sodium $(50 \mathrm{mg} / \mathrm{kg})$ for anesthesia, the animals were sacrificed by cervical dislocation, and the hippocampal tissues of the rats were collected immediately. One part of the collected hippocampus tissues was initially flash-frozen in liquid nitrogen for RT-qPCR, western blot analysis and biochemical examination. The remaining hippocampal tissues were collected for pathological examination.

Celltransfection.PC12 and hippocampal cells $\left(1 \times 10^{6}\right.$ cells/well $)$ were cultured in 6-well plates until reaching $70 \%$ confluence. Lipofectamine 2000 (Invitrogen; Thermo Fisher Scientific, Inc.) was used to perform cell transfection. Cells were transfected with $24 \mathrm{nM}$ miR-130b mimics (miR10000837-1-5; Guangzhou RiboBio Co., Ltd.), negative control (NC) of miRNA mimic (NC mimic; miR1N0000001-1-5; Guangzhou RiboBio Co., Ltd.), miR-130b inhibitor (miR20000837-1-5; Guangzhou RiboBio Co., Ltd.) or NC of miRNA inhibitor (NC inhibitor; miR2N0000001-1-5; Guangzhou RiboBio Co., Ltd.), or $30 \mathrm{nM}$ small interfering RNA (siRNA/si) against PTEN (si-PTEN; siB1142121626-1-5; Guangzhou RiboBio Co., Ltd.) or NC siRNA (si-NC; siN0000002-1-5; Guangzhou RiboBio Co., Ltd.). The cells were collected for further analysis following transfection for $48 \mathrm{~h}$.

Reverse transcription-quantitative PCR (RT-qPCR). Total RNA was isolated from the PC12 cells, hippocampal cells and hippocampal tissue using TRIzol ${ }^{\circledR}$ reagent (Invitrogen; Thermo Fisher Scientific, Inc.). Extracted RNA was reverse transcribed into cDNA for miRNA and mRNA detection using the SuperScript ${ }^{\mathrm{TM}}$ IV First-Strand Synthesis system (Invitrogen; Thermo Fisher Scientific, Inc.) and Mir-X miRNA First-Strand Synthesis kit (Takara Bio, Inc.), respectively. The expression of miR-130b and PTEN was determined by RT-qPCR using a Mir-X miRNA qRT-PCR TB Green ${ }^{\circledR}$ kit or TB Green ${ }^{\circledR}$ Fast qPCR mix (Takara Bio, Inc.), respectively. U6 and GAPDH were used for the normalization of miRNA and mRNA levels, respectively. The results of the RT-qPCR were calculated using the $2^{-\Delta \Delta C q}$ method (26). The thermocycling conditions were as follows: Initial denaturation at $97^{\circ} \mathrm{C}$ for $3 \mathrm{~min}$, followed by 40 cycles at $95^{\circ} \mathrm{C}$ for $15 \mathrm{sec}$ and $60^{\circ} \mathrm{C}$ for $30 \mathrm{sec}$, and melting curve stage at taking fluorescent measurements every $0.5^{\circ} \mathrm{C}$ for $15 \mathrm{sec}$ from $55^{\circ} \mathrm{C}$ until $95^{\circ} \mathrm{C}$. GAPDH was used as a standardized internal control. The primer sequences are presented in Table I.

Dual-luciferase reporter assay. TargetScan (www.targetscan. org) was utilized to predict the binding site between PTEN and miR-130b. Wild-type (Wt) or mutant (Mut) fragments of the 3'-untranslated region (UTR) from PTEN was synthesized by HanBio Co., Ltd., which included the potential miR-130b binding sites. The fragments were then ligated into the psiCheck2 vector (Promega Corporation), and the constructs were named PTEN-Wt and PTEN-Mut, respectively.

For the dual-luciferase reporter assay, 293T cells (cat. no. CL-0005; Procell Life Science \& Technology Co., Ltd.) were seeded at a density of $2 \times 10^{4}$ cells/well in 24 -well plates and cultured in RPMI-1640 medium containing $15 \%$ fetal bovine serum and $1 \%$ penicillin-streptomycin for $24 \mathrm{~h}$. The cells were then co-transfected with $24 \mathrm{nM}$ miR-130b mimic/NC mimic and $50 \mathrm{nM}$ PTEN-Wt/Mut reporter plasmids using Lipofectamine ${ }^{\circledR} 2000$ (Invitrogen; Thermo Fisher Scientific, Inc.). Cells were collected following transfection for 24 h. The Dual-Luciferase Reporter Assay system (Promega Corporation) was used to monitor the luciferase activity. Relative luciferase activity was normalized as the ratio of firefly luciferase activity to Renilla luciferase activity. Each experiment was performed in triplicate.

Cell viability assay. Cell viability was detected using the Cell Counting Kit-8(CCK-8) assay (Dojindo MolecularTechnologies, Inc.). PC12 and hippocampal cells (6,000 cells/well) were seeded into 96-well plates and treated as aforementioned for processing for $48 \mathrm{~h}$. The cells were then incubated in $10 \%$ CCK-8 solution at $37^{\circ} \mathrm{C}$ for $1 \mathrm{~h}$, and the absorbance value was measured at $450 \mathrm{~nm}$ using a microplate reader (Thermo Fisher Scientific, Inc.). Each experiment was performed in triplicate. 
Table I. Sequences of primers used for RT-qPCR.

\begin{tabular}{ll}
\hline Name & \multicolumn{1}{c}{ Sequences $\left(5^{\prime}-3^{\prime}\right)$} \\
\hline miR-130b & Sense: ACTCTTTCCCTGTTGCACTAC \\
& Universal antisense: Mir-X miRNA qRT-PCR TB Green ${ }^{\circledR}$ kit (cat. no. 638314; Clontech, \\
& Takara Bio, Inc.) provided \\
PTEN & Sense: CAATGTTCAGTGGCGAACTT \\
& Antisense: GGCAATGGCTGAGGGAACT \\
U6 & Mir-X miRNA qRT-PCR TB Green ${ }^{\circledR}$ kit (cat. no. 638314; Clontech, Takara Bio, Inc.) provided \\
GAPDH & Sense: TTCCTACCCCCATGTATCCG \\
& Antisense: CATGAGGTCCACCACCCTGTT
\end{tabular}

Apoptosis assay. Cell apoptosis was detected using an Annexin V-FITC/PI Apoptosis Detection kit (Beyotime Institute of Biotechnology) and flow cytometry. Cells were digested with $0.25 \%$ Trypsin-EDTA (Gibco; Thermo Fisher Scientific, Inc.) at $37^{\circ} \mathrm{C}$ for $1 \mathrm{~min}$. The cells were then washed with PBS buffer solution (Gibco; Thermo Fisher Scientific, Inc.), centrifugated at $200 \mathrm{x} \mathrm{g}$ at $4^{\circ} \mathrm{C}$ for $5 \mathrm{~min}$ and double-stained with $10 \mu \mathrm{l}$ Annexin V-FITC/PI mix for $15 \mathrm{~min}$ at room temperature in the dark. Subsequently, the cells were evaluated by a FACSCalibur ${ }^{\mathrm{TM}}$ Flow Cytometer (BD Biosciences) and analyzed using Cell Quest 3.3 software (BD Biosciences). The total apoptotic rate of the cells was defined as the sum of both early apoptosis (Annexin V-FITC-positive, PI-negative) and late apoptosis (Annexin V-FITC- and PI-positive). Each experiment was performed in triplicate.

Western blot analysis. Total protein was isolated from the PC12 cells, hippocampal cells and hippocampal tissue using radioimmunoprecipitation assay lysis buffer (Beyotime Institute of Biotechnology). Bicinchoninic acid assay (Thermo Fisher Scientific, Inc.) was used to quantify proteins. Subsequently, proteins (30 $\mu \mathrm{g}$ per lane) were mixed with loading buffer (Beijing Solarbio Science \& Technology Co., Ltd.), boiled for $15 \mathrm{~min}$ and separated by $10 \%$ SDS-PAGE (Beyotime Institute of Biotechnology). The proteins were transferred to PVDF membranes (Millipore Sigma). After blocking with $5 \%$ skim milk for $1 \mathrm{~h}$ at room temperature, the PVDF membranes were incubated at $4^{\circ} \mathrm{C}$ overnight with the corresponding primary antibodies, including anti-PTEN (1:1,000; cat. no. ab267787; Abcam), anti-Akt (1:500; cat. no. ab8805; Abcam), anti-phosphorylated (p)-Akt (1:500; cat. no. ab38449; Abcam), anti-Bcl-2 (1:500; cat. no. ab59348; Abcam), anti-Bax (1:2,000; cat. no. ab32503; Abcam), anti-cleaved caspase-3 (1:500; cat. no. ab49822; Abcam), anti-caspase-3 (1:1,000; cat. no. 9662; Cell Signaling Technology, Inc.) and anti- $\beta$-actin (1:1,000; cat. no. ab8227; Abcam). The PVDF membranes were then washed and further incubated with a secondary antibody conjugated to horseradish peroxidase (1:2,000; cat. no. ab205718; Abcam) for $1 \mathrm{~h}$ at room temperature. SuperSignal West Pico Plus (Thermo Fisher Scientific, Inc.) was employed to visualize the protein bands. Image-Pro Plus 6.0 (Media Cybernetics, Inc.) was used to semi-quantify the relative band intensities. $\beta$-actin was employed for normalization of relative protein expression. Each experiment was performed in triplicate.

Biochemical detection. PC12 and hippocampal cells were lysed at $4^{\circ} \mathrm{C}$ using an ultrasonic cell disruptor and centrifuged at $200 \mathrm{x} \mathrm{g}$ at $4^{\circ} \mathrm{C}$ for $10 \mathrm{~min}$. A total of $100 \mu \mathrm{l}$ supernatant of each group was obtained to detect the optical density values using a microplate reader (spectra max PLUS 384, Molecular Devices, LLC) according to the instructions of the superoxide dismutase (SOD) assay kit (Nanjing Jiancheng Bioengineering Institute) $(450 \mathrm{~nm})$ and the malondialdehyde (MDA) assay kit (Nanjing Jiancheng Bioengineering Institute) $(532 \mathrm{~nm})$.

The hippocampal tissues collected as aformenetioned were shredded using an ophthalmic scissor. Normal saline was then added to produce a $10 \%$ brain tissue homogenate. The homogenate was centrifuged at $200 \mathrm{x}$ g at $4^{\circ} \mathrm{C}$ for $10 \mathrm{~min}$, and the supernatant was obtained for future use. The activity of SOD and the content of MDA were detected using a colorimetric method according to the instructions provided with the aforementioned kits.

Behavioral assessment. A step-down passive avoidance test was used to detect the cognitive competence of the rats $(27,28)$. The test was performed in a plexiglass cage $(20 \times 20 \times 20 \mathrm{~cm})$ with a rubber platform $(8.0 \times 8.0 \times 4.5 \mathrm{~cm})$ in the corner. In the training session, the rats were placed in the plexiglass cage for $3 \mathrm{~min}$ to explore the box freely. The rats were then exposed to an electric shock $(36 \mathrm{~V})$ until they stepped onto the rubber platform. After $24 \mathrm{~h}$, the rats were again placed onto the rubber platform, and the step-down latency and number of errors within 5 min were recorded.

Pathological examination. The hippocampal tissues were fixed with $4 \%$ paraformaldehyde for $48 \mathrm{~h}$ and prepared into $5-\mu \mathrm{m}$-thick paraffin sections. The pathological changes in the hippocampus tissues were stained using a hematoxylin and eosin (H\&E) staining kit (Beyotime Institute of Biotechnology). Briefly, the sections were stained with hematoxylin for $2 \mathrm{~min}$ and stained with eosin for $10 \mathrm{~min}$ at room temperature. Following dehydration with gradient alcohol, the sections were sealed using neutral resin and observed under a microscope (BA400Digital; Motic Group Co., Ltd.). The apoptotic cells in the hippocampal tissues were stained using a TUNEL assay kit (Roche Applied Science). Briefly, the sections were incubated 
A

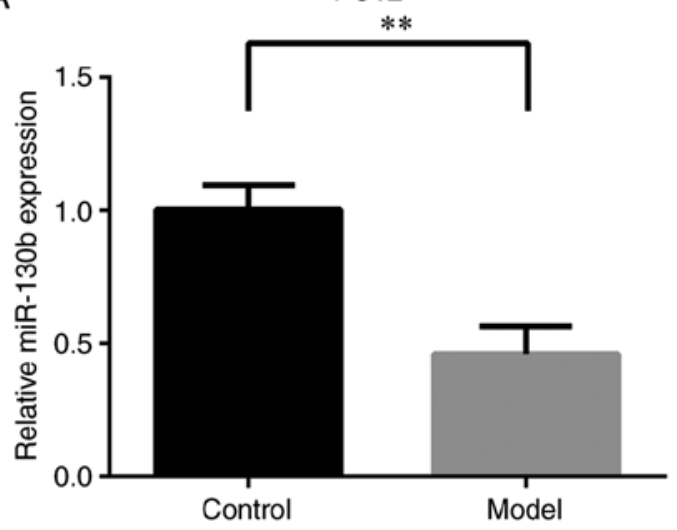

B

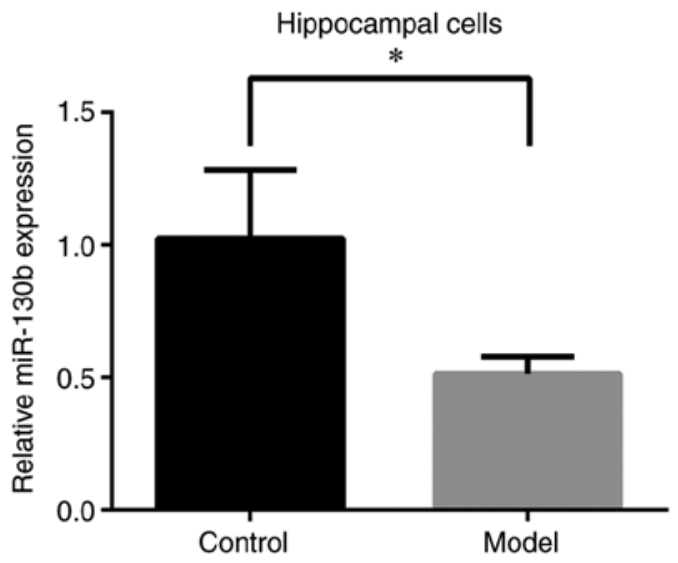

Figure 1. Expression of miR-130b in high glucose-stimulated cells. (A) Expression of miR-130b in PC12 cells. (B) Expression of miR-130b in hippocampal cells. For high glucose conditions, cells were cultured in the RPMI-1640 medium containing $15 \% \mathrm{FBS}$ and $75 \mathrm{mM}$ glucose for $72 \mathrm{~h} .{ }^{*} \mathrm{P}<0.05,{ }^{* *} \mathrm{P}<0.01$. miR, microRNA; FBS, fetal bovine serum.

with protease $\mathrm{K}$ for $30 \mathrm{~min}$ at $25^{\circ} \mathrm{C}$ and washed by PBS twice. The sections were then incubated with TUNEL reaction mixture at $37^{\circ} \mathrm{C}$ for $1 \mathrm{~h}$ and washed three times with PBS. Thereafter, the sections were incubated with converter-POD at $37^{\circ} \mathrm{C}$ for $30 \mathrm{~min}$. Following three PBS washes, the sections were added to Substrate solution and incubated at $20^{\circ} \mathrm{C}$ for 25 min. Ultrastructural damage of the hippocampus was observed using a transmission electron microscope (TEM). Briefly, the hippocampal tissues were pre-fixed with $3 \%$ glutaraldehyde (Sigma-Aldrich LLC.) and then fixed with $1 \%$ osmium (VIII) oxide (Electron Microscopy China, EMCN ${ }^{\mathrm{TM}}$ ). Subsequently, the hippocampal tissues were dehydrated with acetone, embedded in epoxy resins $\left(\mathrm{EMCN}^{\mathrm{TM}}\right)$ and sliced for 50-nm-thick slices by an ultratome (EM UC7, Leica Inc.). The ultra-thin slices were loaded on a formvar/carbon coated grid $\left(\mathrm{EMCN}^{\mathrm{TM}}\right)$, and stained with uranium acetate $\left(\mathrm{EMCN}^{\mathrm{TM}}\right)$ and lead citrate $\left(\mathrm{EMCN}^{\mathrm{TM}}\right)$ at room temperature for $15-20 \mathrm{~min}$. Finally, the slices were observed under a JEM-1400 Flash electron microscope (JEOL Ltd.).

Statistical analysis. Data are presented as the mean \pm standard deviation. Experiments were repeated three times. Statistical evaluations and calculations were performed with SPSS 22.0 (IBM Corp.). Differences of data were evaluated using an independent-samples t-test between two groups or one-way analysis of variance followed by a Turkey's post hoc analysis among multiple groups. $\mathrm{P}<0.05$ was considered to indicate a statistically significant difference.

\section{Results}

High glucose stimulation reduces the expression of $\mathrm{miR}-130 \mathrm{~b}$ in PC12 and hippocampal cells. To examine the effects of high glucose on the expression of miR-130b in PC12 and hippocampal cells, RT-qPCR was performed to detect the miR-130b levels. As shown in Fig. 1A and B, compared with that of the control group, the expression of miR-130b in $\mathrm{PC} 12$ and hippocampal cells under a high glucose environment was significantly decreased $(\mathrm{P}<0.01$ or $\mathrm{P}<0.05$, respectively). These results indicated that high glucose stimulation inhibited miR-130b expression in PC12 and hippocampal cells.
Overexpression of miR-130b promotes cell viability and inhibits apoptosis, while miR-130b silencing inhibits cell viability and promotes the apoptosis of PC12 and hippocampal cells under an elevated glucose environment. To further investigate the role of miR-130b in PC12 and hippocampal cells in a high glucose environment, miR-130b was overexpressed using a miR-130b mimic, and miR-130b was silenced using a miR-130 inhibitor. As shown in Fig. 2A, the expression of miR-130b in PC12 and hippocampal cells was increased following miR-130b mimic transfection $(\mathrm{P}<0.01)$. The expression of miR-130b was decreased following incubation with miR-130b inhibitor $(\mathrm{P}<0.01)$.

CCK-8 assay was performed to detect the effects of miR-130b on the viability of PC12 and hippocampal cells in a high glucose environment. As shown in Fig. 2B, compared with that of the control group, cell viability was significantly decreased in the model group $(\mathrm{P}<0.01)$. The overexpression of miR-130b increased cell viability, while the inhibition of miR-130b reduced the viability of $\mathrm{PC} 12$ and hippocampal cells in a high glucose environment $(\mathrm{P}<0.05)$.

The present study also explored the effects of miR-130b on the apoptosis of PC12 and hippocampal cells under high glucose conditions. As shown in Fig. 2C, compared with that of the control group, the apoptotic rate of the model group was significantly increased $(\mathrm{P}<0.01)$. The overexpression of miR-130b decreased the apoptotic rate, while the inhibition of miR-130b increased the apoptotic rate of PC12 and hippocampal cells in a high glucose environment $(\mathrm{P}<0.01)$. These results demonstrated that miR-130b attenuated high glucose-induced cell damage.

PTEN is the target gene of miR-130b in PC12 and hippocampal cells. To further explore the mechanisms of action of miR-130b, TargetScan was used to predict the potential targets of miR-130b. It was found that PTEN was a potential target of miR-130b (Fig. 3A). To confirm the potential targeting association between miR-130b and PTEN, a dual-luciferase reporter assay was performed. miR-130b mimic and PTEN-Wt or Mut were co-transfected into 293T cells. The data indicated that the overexpression of miR-130b reduced the luciferase activity of PTEN-Wt $(\mathrm{P}<0.01)$, but not 

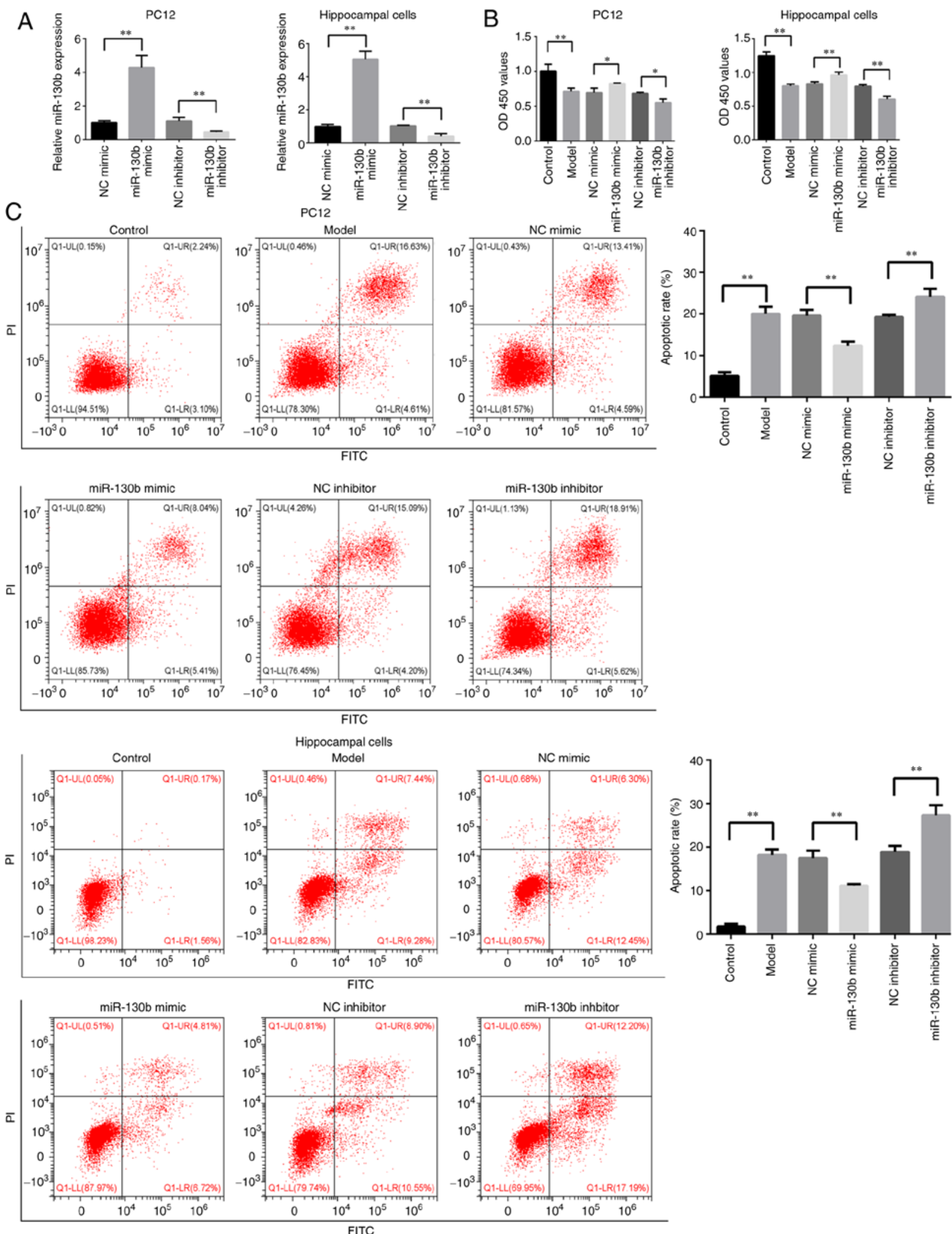

Figure 2. Effect of miR-130b on the viability and apoptosis of high glucose-stimulated cells. (A) The transfection efficiency of miR-130b mimic and miR-130b inhibitor was detected using reverse transcription-quantitative PCR. (B) PC12 and hippocampal cells were incubated with NC mimic, miR-130b mimic, NC inhibitor or miR-130b inhibitor, followed by treatment with high glucose. Cell viability was determined using a Cell Counting Kit-8 assay. (C) Cell apoptosis was detected using flow cytometry. Data were obtained from three independent experiments. The results are presented as the mean \pm standard deviation. ${ }^{*} \mathrm{P}<0.05,{ }^{* * *} \mathrm{P}<0.01$. Model, cells were cultured under high glucose conditions. For high glucose conditions, cells were cultured in the RPMI-1640 medium containing $15 \%$ FBS and $75 \mathrm{mM}$ glucose for $72 \mathrm{~h}$. miR, microRNA; NC, negative control; FBS, fetal bovine serum.

that of PTEN-Mut (Fig. 3B). Furthermore, to examine the effects of miR-130b on PTEN mRNA expression in PC12 and hippocampal cells, a RT-qPCR assay was performed. As shown in Fig. 3C, miR-130b mimic significantly inhibited 
A
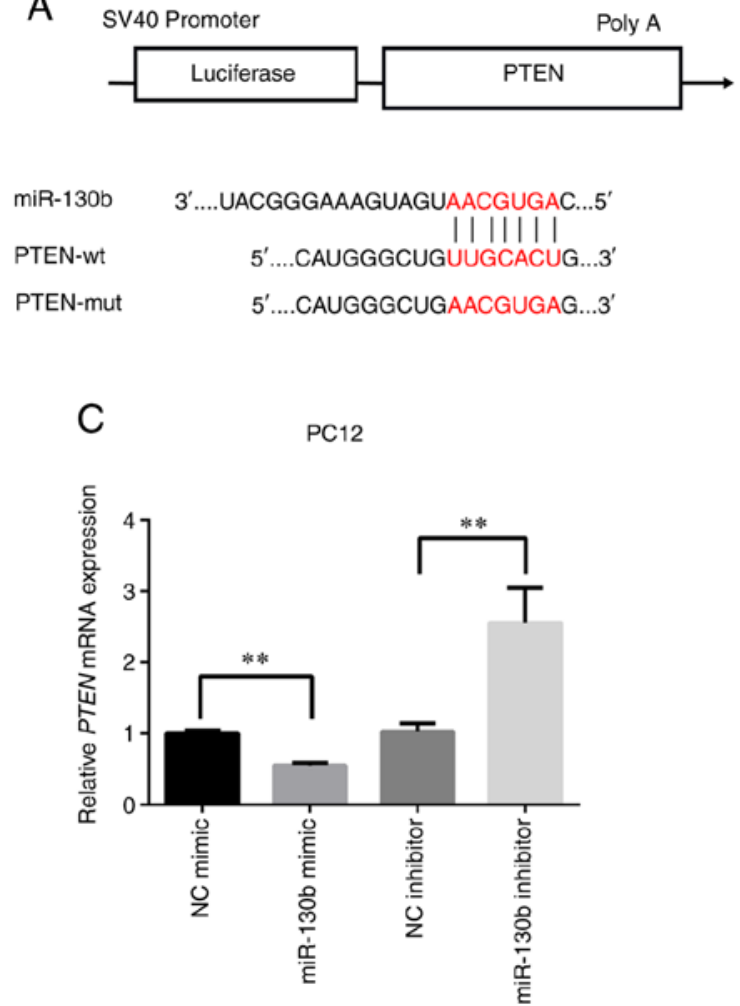

B
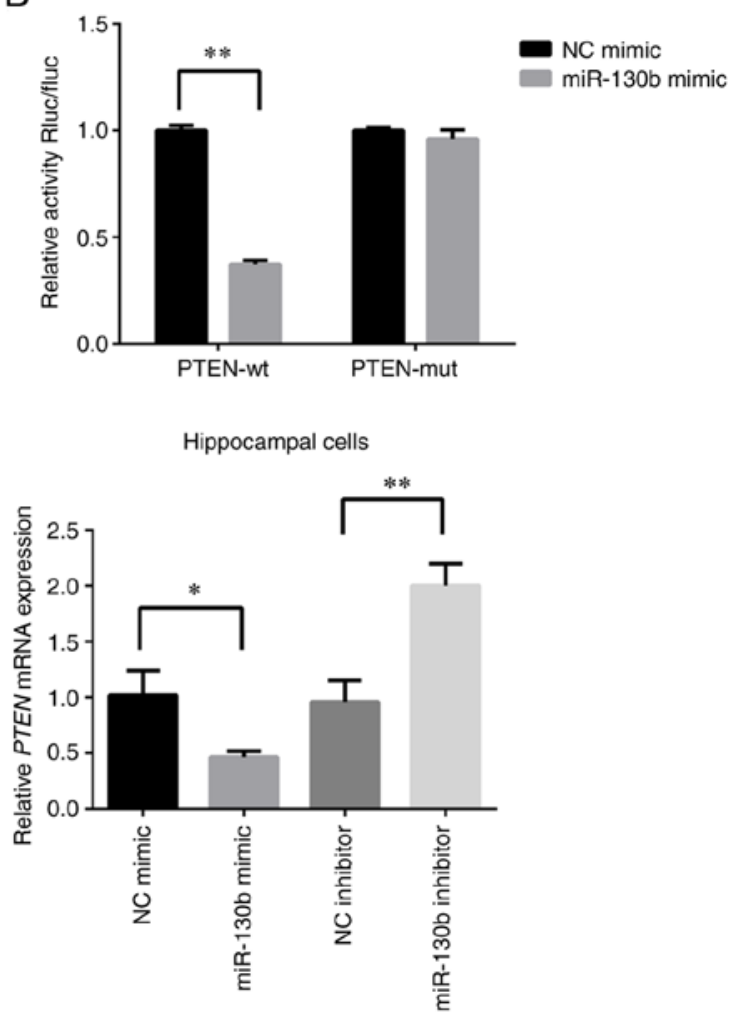

Figure 3. PTEN is the direct target of miR-130b in PC12 and hippocampal cells. (A) Sequence of binding sites between PTEN-3'-UTR and miR-130b. (B) Relative luciferase activities were detected in 293T cells co-transfected with PTEN 3'-UTR (Wt or mut) reporter plasmid, miR-130b mimic or NC mimic. (C) Reverse transcription-quantitative PCR analysis of PTEN mRNA expression in PC12 and hippocampal cells transfected with miR-130b mimic, NC mimic, miR-130b inhibitor and NC inhibitor. U6 served as the reference gene. ${ }^{*} \mathrm{P}<0.05,{ }^{* *} \mathrm{P}<0.01$. PTEN, phosphatase and tensin homolog; UTR, untranslated region; miR, microRNA; Wt, wild-type; mut, mutant; NC, negative control.

the expression of PTEN $(\mathrm{P}<0.01)$, while miR-130b inhibitor enhanced the mRNA expression of PTEN $(\mathrm{P}<0.05)$. These results demonstrated that $\mathrm{PTEN}$ was the target gene of miR-130b in PC12 and rat hippocampal cells.

Silencing of PTEN promotes the viability, and inhibits the apoptosis of PC12 and hippocampal cells in a high glucose environment. To examine the effects of high glucose on the expression of PTEN in PC12 and hippocampal cells, RT-qPCR was performed to detect the PTEN levels. As shown in Fig. 4A, compared with that of the control group, the expression of PTEN in PC12 and hippocampal cells in a high glucose environment was significantly increased $(\mathrm{P}<0.05)$. Subsequently, si-PTEN was synthesized, and it was determined that si-PTEN could effectively interfere with PTEN mRNA expression in PC12 and hippocampal cells $(\mathrm{P}<0.05$ or $\mathrm{P}<0.01$, respectively; Fig. $4 \mathrm{~B})$. CCK-8 assay was then performed to detect the effects of PTEN on the viability of PC12 and hippocampal cells in a high glucose environment. As shown in Fig. 4C, the inhibition of PTEN increased the viability of PC12 and hippocampal cells in a high glucose environment $(\mathrm{P}<0.05$ or $\mathrm{P}<0.01$, respectively), and partly reversed the effects of the miR-130b inhibitor on the reduction of cell viability $(\mathrm{P}<0.01)$. Furthermore, the present study explored the role of PTEN in the apoptosis of PC12 and hippocampal cells under high glucose conditions. As shown in Fig. 4D, the inhibition of PTEN reduced the apoptotic rate of PC12 and hippocampal cells in a high glucose environment, and partly abrogated the promoting effects of miR-130b inhibitor on apoptosis $(\mathrm{P}<0.05$ or $\mathrm{P}<0.01$, respectively). These results indicated that $\mathrm{miR}-130 \mathrm{~b}$ regulated PTEN to attenuate high glucose-induced cell damage.

miR-130b regulates PTEN to strengthen the antioxidant capacity of PC12 and hippocampal cells in an elevated glucose environment. As shown in Fig. 5A and B, compared with that of the control group, the activity of SOD in PC12 and hippocampal cells of the model group was decreased $(\mathrm{P}<0.05$ or $\mathrm{P}<0.01$, respectively), while the content of MDA was markedly increased ( $\mathrm{P}<0.05$ or $\mathrm{P}<0.01$, respectively). Compared with those of the model group, the miR-130b mimic and si-PTEN groups displayed a reduced content of MDA ( $\mathrm{P}<0.05$ or $\mathrm{P}<0.01$, respectively) and an increased SOD activity $(\mathrm{P}<0.05$ or $\mathrm{P}<0.01$, respectively), while the miR-130b inhibitor group exhibited an increased MDA content $(\mathrm{P}<0.05)$ and a decreased activity of SOD $(\mathrm{P}<0.05)$. Compared with those of the miR-130b inhibitor group, the miR-130b inhibitor + si-PTEN group displayed an increased SOD activity $(\mathrm{P}<0.05$ or $\mathrm{P}<0.01$, respectively) and a reduced content of MDA $(\mathrm{P}<0.01)$. These results indicated that miR-130b regulated PTEN and promoted the antioxidant capacity of PC12 and hippocampal cells in an elevated glucose environment.

miR-130b regulates PTEN expression to activate Akt and inhibit the mitochondria-mediated apoptosis pathway in 

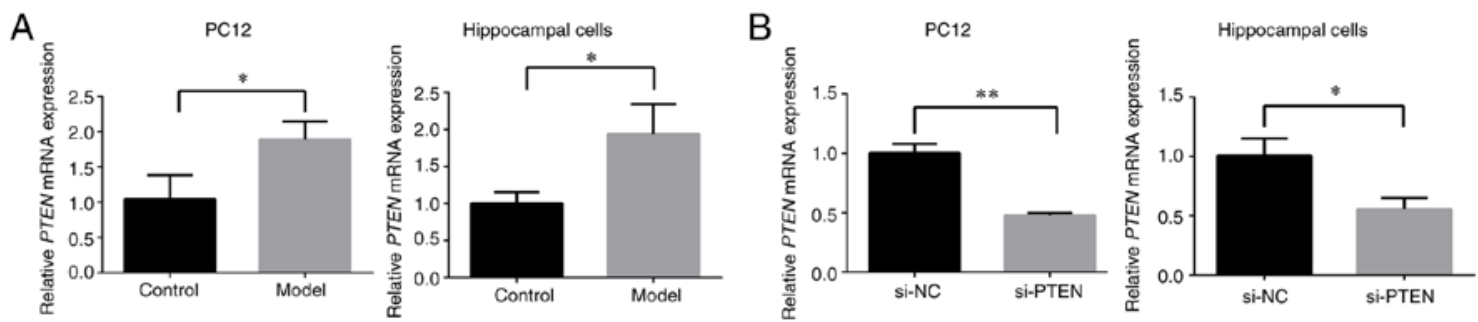

C
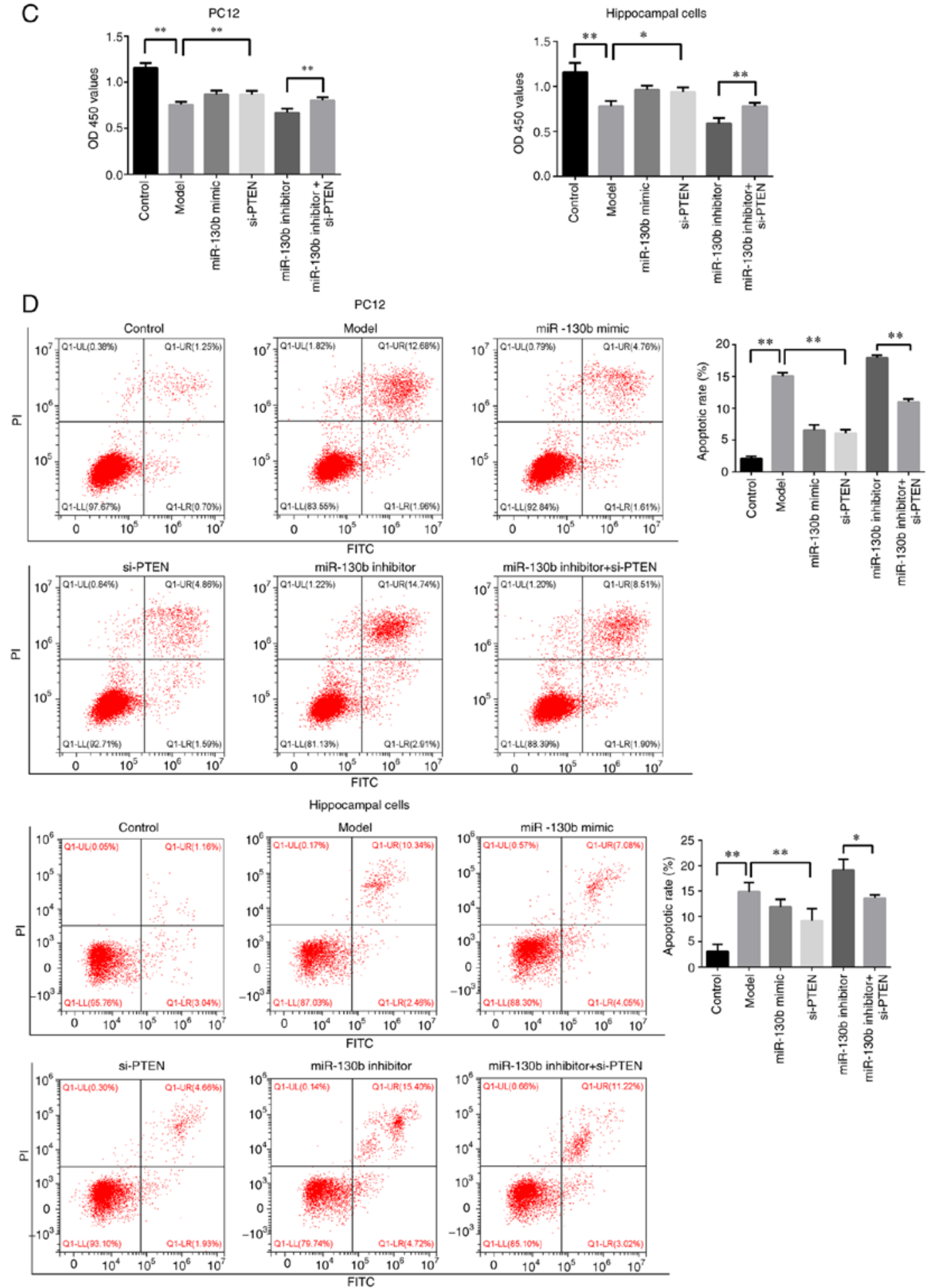

Figure 4. Effect of the miR-130b/PTEN axis on cell viability and apoptosis in high glucose-stimulated cells. (A) The expression of PTEN was detected by RT-qPCR in high glucose-stimulated cells. (B) The transfection efficiency of si-PTEN was detected using RT-qPCR. (C) PC12 and hippocampal cells were incubated with miR-130b mimic, si-PTEN, miR-130b inhibitor or miR-130b inhibitor + si-PTEN, followed by treatment with high glucose. Cell viability was determined by Cell Counting Kit- 8 assay. (D) Cell apoptosis was detected using flow cytometry. Data were acquired from three independent experiments. The results are presented as the mean \pm standard deviation. ${ }^{*} \mathrm{P}<0.05,{ }^{* *} \mathrm{P}<0.01$. Model, cells were cultured under high glucose conditions; RT-qPCR, reverse transcription-quantitative PCR; PTEN, phosphatase and tensin homolog; miR, microRNA; si, small interfering RNA. 

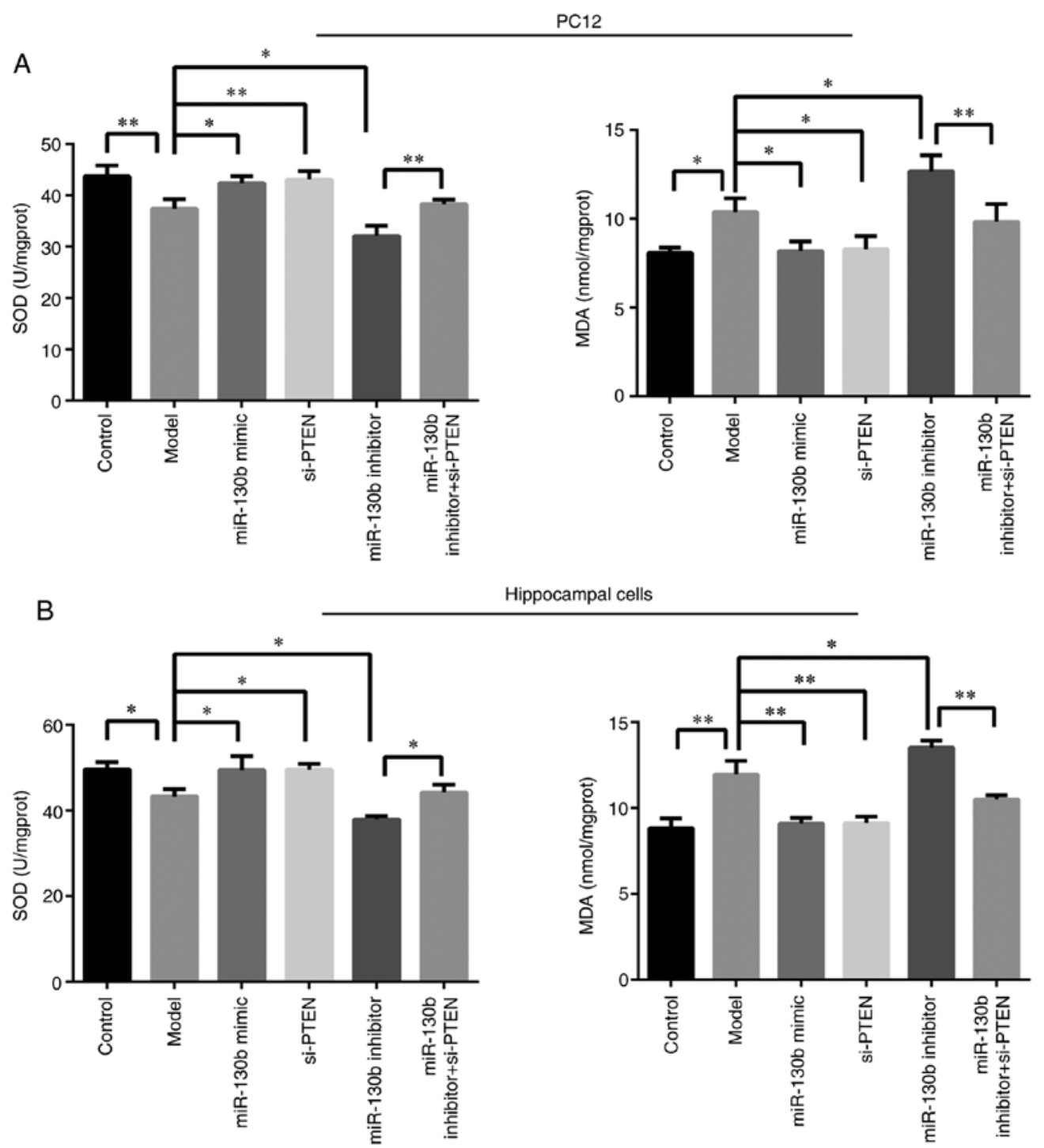

Figure 5. The microRNA-130b/phosphatase and tensin homolog axis enhances the antioxidant capacity to protect cells from oxidative stress damage in vitro. SOD activity and MDA content in (A) PC12 cells and (B) hippocampal cells. Data were acquired from three independent experiments. The results are presented as the mean \pm standard deviation. ${ }^{*} \mathrm{P}<0.05,{ }^{* *} \mathrm{P}<0.01$. model, cells cultured under high glucose conditions; $\mathrm{SOD}$, superoxide dismutase; MDA, malondialdehyde.

PC12 and hippocampal cells in a high glucose environment. The results of western blot analysis are illustrated in Fig. 6A. Compared with that of the control group, the expression of PTEN was significantly increased $(\mathrm{P}<0.01$; Fig. 6B), while the ratio of $\mathrm{p}-\mathrm{Akt} / \mathrm{Akt}$ was decreased in the model group $(\mathrm{P}<0.01$; Fig. 6C). Compared with that of the model group, the expression of PTEN was significantly decreased $(\mathrm{P}<0.05$ or $\mathrm{P}<0.01$, respectively; Fig. 6B), and the ratio of p-Akt/Akt was increased $(\mathrm{P}<0.01$; Fig. 6C) in the miR-130b mimic and si-PTEN groups, while the expression of PTEN was increased $(\mathrm{P}<0.05$ or $\mathrm{P}<0.01$, respectively; Fig. $6 \mathrm{~B}$ ) and the ratio of $\mathrm{p}-\mathrm{Akt} / \mathrm{Akt}$ was significantly reduced $(\mathrm{P}<0.05$ or $\mathrm{P}<0.01$, respectively; Fig. 6C) in the miR-130b inhibitor group. Compared with that of the miR-130b inhibitor group, the expression of PTEN was decreased $(\mathrm{P}<0.01$; Fig. $6 \mathrm{~B})$ and the ratio of p-Akt/Akt was increased in the miR-130b inhibitor + si-PTEN group $(\mathrm{P}<0.01$; Fig. 6C). Furthermore, the expression of mitochondria-mediated apoptosis pathway-related proteins was detected. Compared with that of the control group, the ratios of Bax/Bcl-2 and cleaved caspase-3/caspase-3 were significantly increased in the model group $(\mathrm{P}<0.01$; Fig. $6 \mathrm{D}$ and $\mathrm{E})$. Compared with that of the model group, the ratios of $\mathrm{Bax} / \mathrm{Bcl}-2$ and cleaved caspase- $3 /$ caspase -3 were decreased in the miR-130b mimic and si-PTEN groups $(\mathrm{P}<0.01$ or $\mathrm{P}<0.05$, respectively; Fig. $6 \mathrm{D}$ and $\mathrm{E}$ ), while the ratios of $\mathrm{Bax} / \mathrm{Bcl}-2$ and cleaved caspase-3/caspase- 3 were significantly increased in the miR-130b inhibitor group $(\mathrm{P}<0.01$ or $\mathrm{P}<0.05$, respectively; Fig. 6D and E). Compared with that of the miR-130b inhibitor group, the ratios of $\mathrm{Bax} / \mathrm{Bcl}-2$ and cleaved caspase-3/caspase-3 were decreased in the miR-130b inhibitor + si-PTEN group $(\mathrm{P}<0.01$; Fig. $6 \mathrm{D}$ and $\mathrm{E})$. These results indicated that the activity of Akt was inhibited and the mitochondria-mediated apoptosis pathway was promoted in PC12 and hippocampal cells under a high glucose environment, and that miR-130b could inhibit PTEN to reverse the high glucose-induced decreased Akt activity and mitochondria-mediated apoptosis.

miR-130b enhances the learning ability of rats with $D E$. The step-down passive avoidance test was performed to detect the learning ability of rats with DE following miR-130b treatment. 

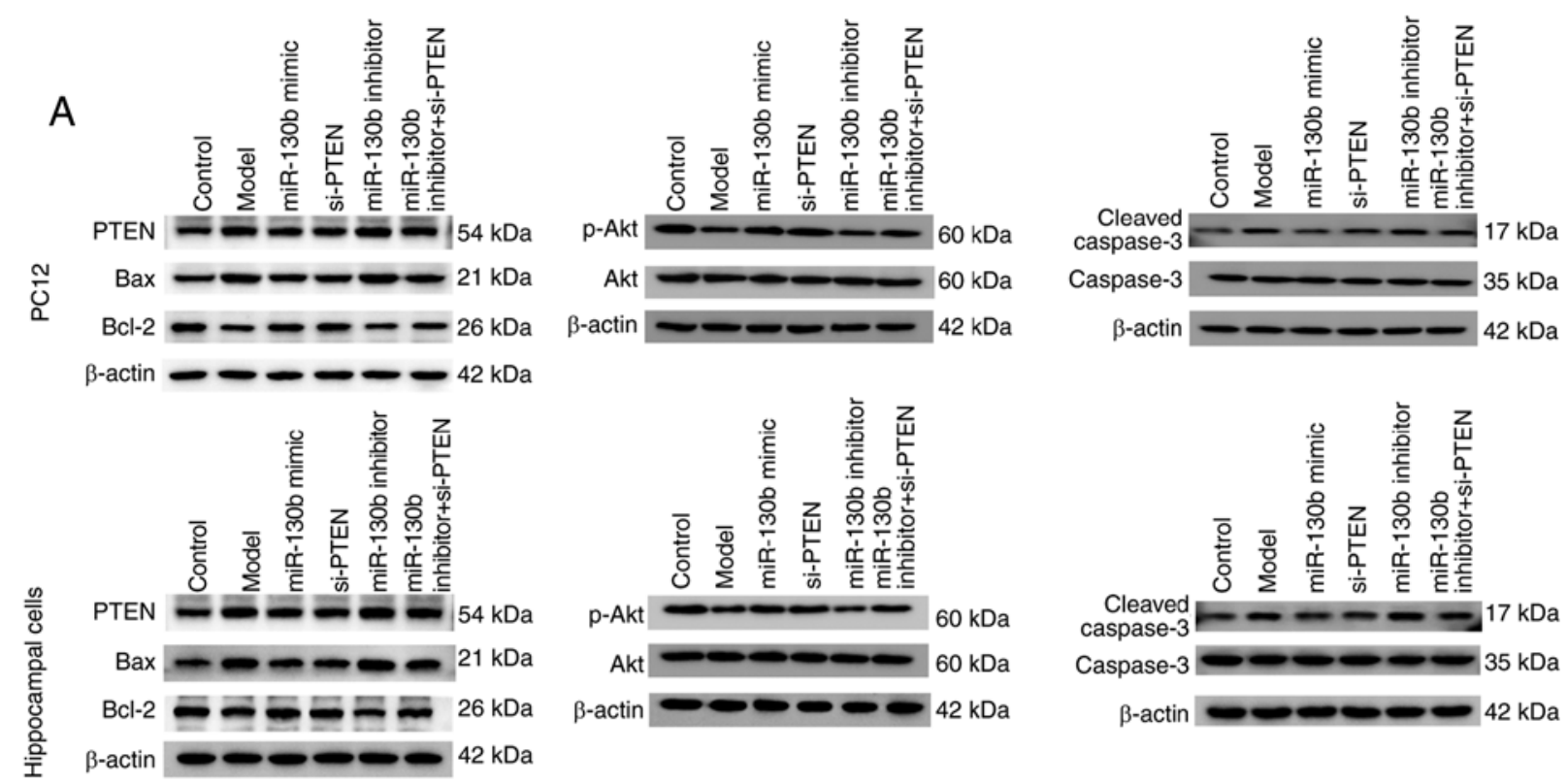

B

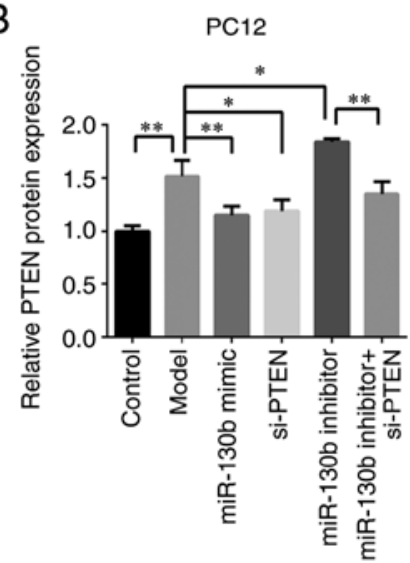

D

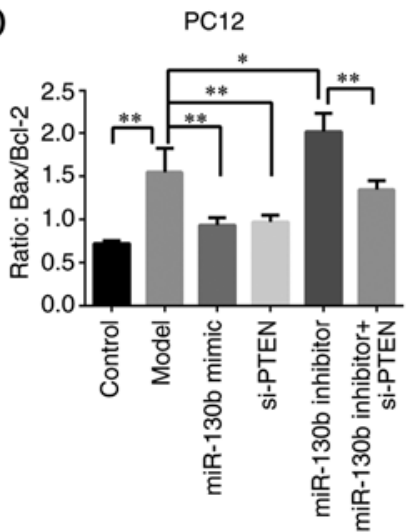

Hippocampal cells

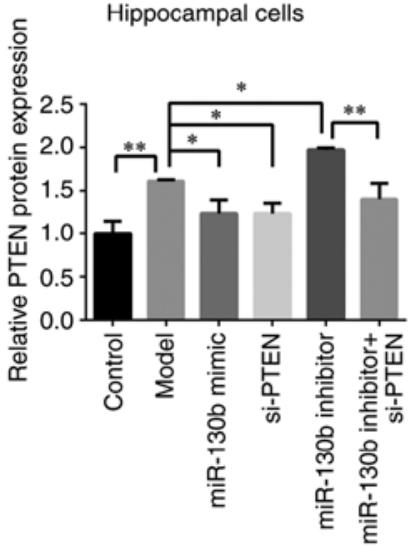

C

PC12

Hippocampal cells

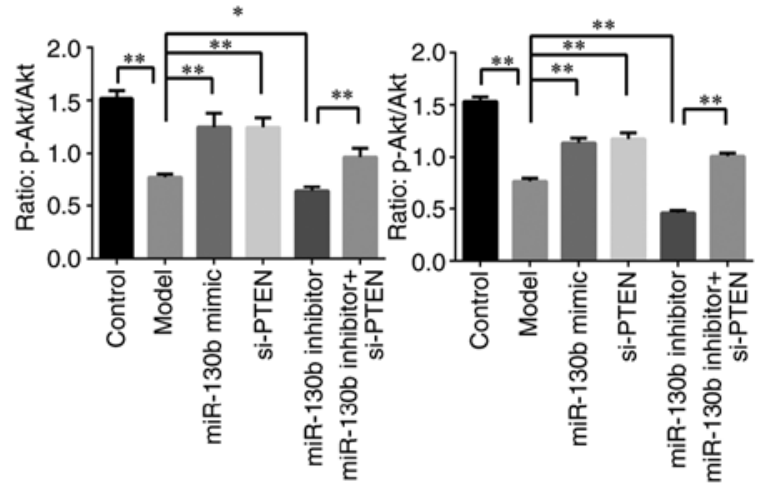

Hippocampal cells

E

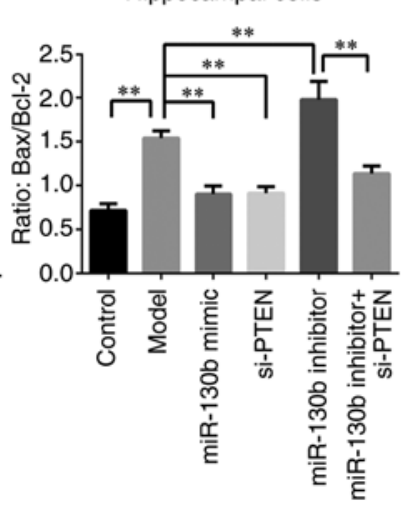

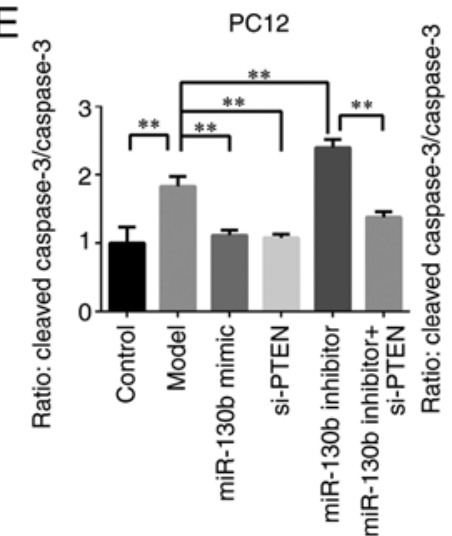

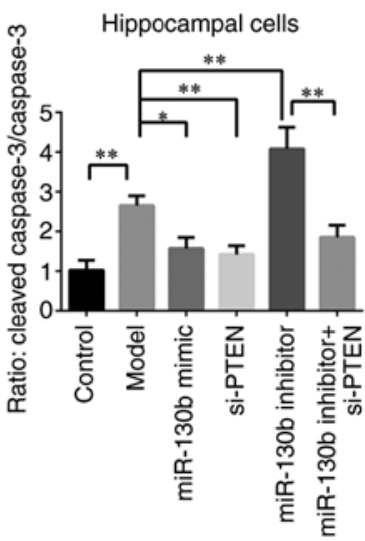

Figure 6. Effect of the miR-130b/PTEN axis on the activity of Akt and the mitochondria-mediated apoptosis pathway. (A) PC12 and hippocampal cells were transfected with miR-130b mimic, si-PTEN, miR-130b inhibitor or miR-130b inhibitor + si-PTEN, followed by treatment with high glucose. Protein expression was evaluated by western blot analysis. (B) Relative expression of PTEN in each group. (C) Activation of Akt is shown as the relative intensity of phosphorylated-Akt to Akt. (D) Activation of apoptosis is shown as the relative intensity ratio of Bax to Bcl-2. (E) Relative intensity ratio of cleaved caspase-3 to caspase-3 in each group. Data were acquired from three independent experiments. The results are presented as the mean \pm standard deviation. ${ }^{\text {"P }}<0.05$, ${ }^{* *} \mathrm{P}<0.01$. PTEN, phosphatase and tensin homolog; miR, microRNA; si, small interfering RNA.

As shown in Fig. 7A and B, compared with those of the control group, the model and agomir-NC groups showed decreased latency time and increased error numbers. Compared with the findings in the agomir-NC group, the step-down latency time was increased, while the number of errors was reduced, in the agomir-130b group $(\mathrm{P}<0.01)$. The present study then examined the effect of miR-130b on the blood glucose content of rats with DE. As shown in Fig. 7C, compared with that of the control group, the content of blood glucose was increased in the model, agomir-NC and agomir-130b groups $(\mathrm{P}<0.01)$. In addition, 

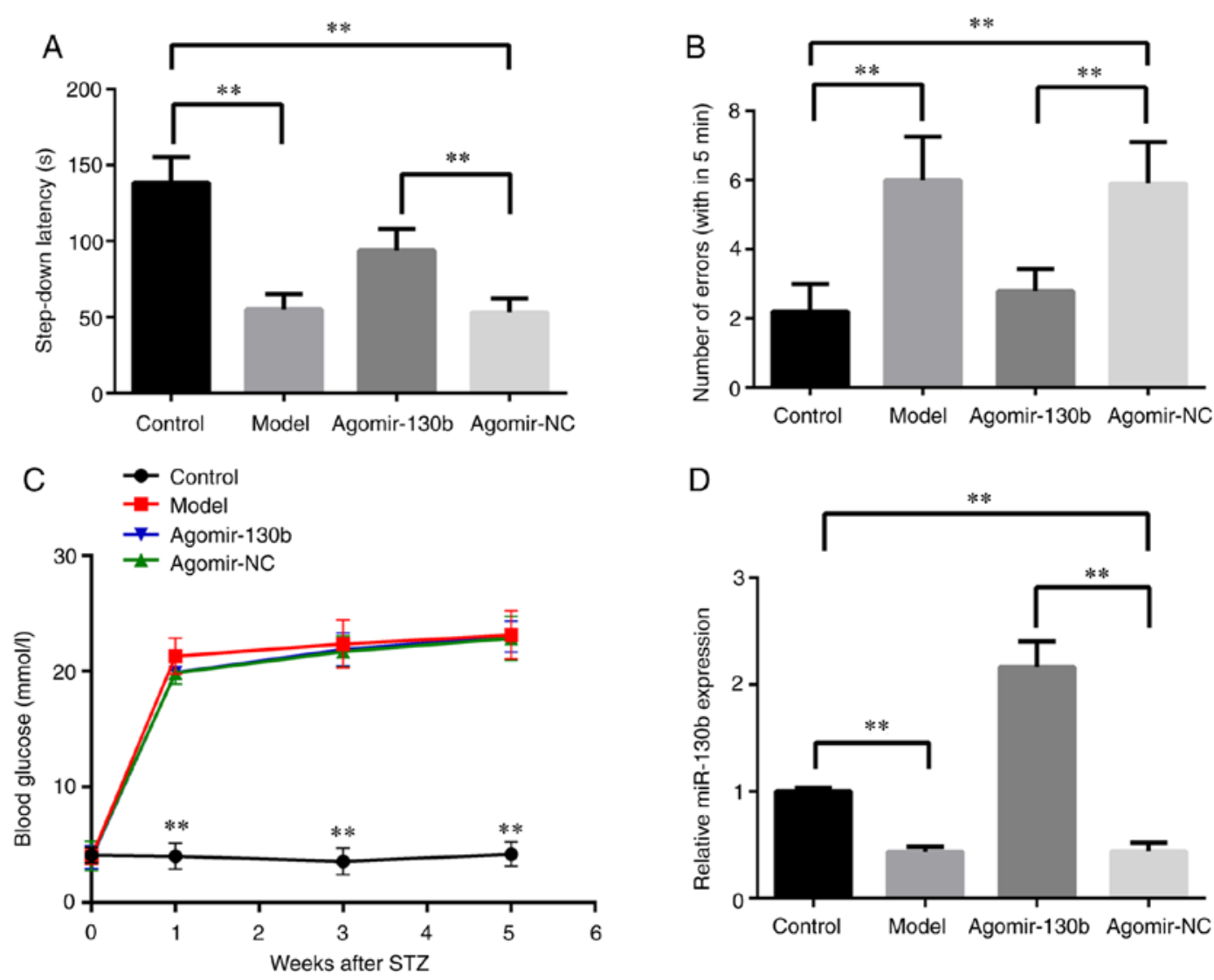

Figure 7. Effects of miR-130b on step-down passive avoidance performance and blood glucose in rats with diabetic encephalopathy. (A) miR-130b affects the step-down latency time of rats in each group. (B) miR-130b affects the step-down error times of rats in each group. (C) Blood glucose levels of rats in each group. (D) The expression of miR-130b was detected in hippocampus. The results are presented as the mean \pm standard deviation. ${ }^{* *} \mathrm{P}<0.01$. miR, microRNA.

the expression of miR-130b in the hippocampus of rats was detected. As shown in Fig. 7D, compared with that of the control group, the model and agomir-NC groups exhibited a decreased miR-130b expression $(\mathrm{P}<0.01)$. Compared with that of the agomir-NC group, the expression of miR-130b was increased in the agomir-130b group $(\mathrm{P}<0.01)$. These results indicated that miR-130b promoted the learning ability, whereas it did not affect the content of blood glucose of rats with DE.

miR-130b attenuates hippocampus neuronal damage in rats with DE. Pathological changes in the hippocampus were detected using H\&E staining (Fig. 8A). Compared with those of the control and agomir-130b groups, the model and agomir-NC groups exhibited a substantially reduced numer of pyramidal cells, and the nucleus was solidified and exhibited increased positive staining. The ultrastructural damage to the hippocampus was observed using TEM (Fig. 8B). The control and agomir-130 groups exhibited a clear nuclear membrane, obvious nucleolus, abundant organelles and a complete synaptic structure. The model and agomir-NC groups exhibited an irregular nucleolus, mitochondrial swelling, rough endoplasmic reticulum dilatation, autophagy and a damaged synaptic structure. Apoptotic cells were detected using TUNEL staining (Fig. 8C). Compared with that of the control group, the apoptotic rate of the model and agomir-NC groups was significantly increased $(\mathrm{P}<0.01)$. Compared with that of the agomir-NC group, the apoptotic rate of the agomir-130b group was significantly reduced
$(\mathrm{P}<0.01)$. These results demonstrated that miR-130b attenuated damage to hippocampal neurons and the apoptosis of hippocampal cells in rats with DE.

miR-130b improves oxidative stress in the hippocampus of rats with $D E$. As shown in Fig. 9A and B, compared with that of the control group, the activity of SOD in the hippocampus of the model and agomir-NC groups was markedly decreased, while the content of MDA was increased $(\mathrm{P}<0.01)$. Compared with those of the agomir-NC group, the agomir-130 group showed increased activity of SOD $(\mathrm{P}<0.01)$ and decreased content of MDA $(\mathrm{P}<0.05)$. These data indicated that miR-130b may improve oxidative stress in the hippocampus of rats with DE.

miR-130b activates Akt protein and inhibits the mitochondria-mediated apoptosis pathway in the hippocampus of rats with $D E$. The results of western blot analysis are presented in Fig. 10A. Compared with that of the control group, the expression of PTEN in the model and agomir-NC groups was markedly increased, while the ratio of p-Akt/Akt was reduced $(\mathrm{P}<0.01)$. Compared with that of the agomir-NC group, the expression of PTEN was significantly increased $(\mathrm{P}<0.05$; Fig. 10B) and the ratio of p-Akt/Akt was decreased in the agomir-130b group ( $\mathrm{P}<0.05$; Fig. 10C). In addition, compared with that of the control group, the ratios of $\mathrm{Bax} / \mathrm{Bcl}-2$ and cleaved caspase-3/caspase-3 were significantly increased in the model and agomir-NC groups $(\mathrm{P}<0.01)$. Compared with that 
A

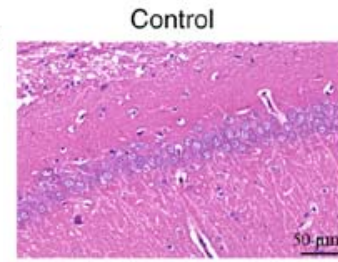

B

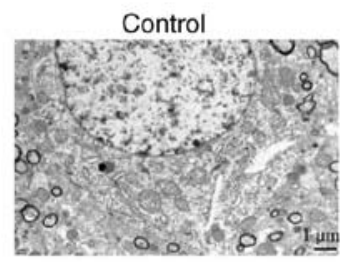

C

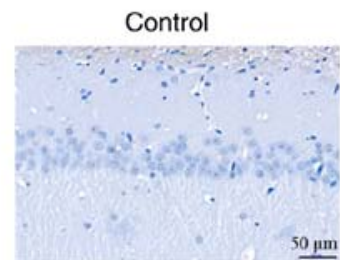

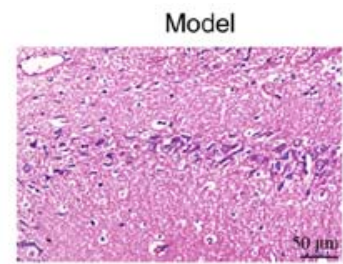
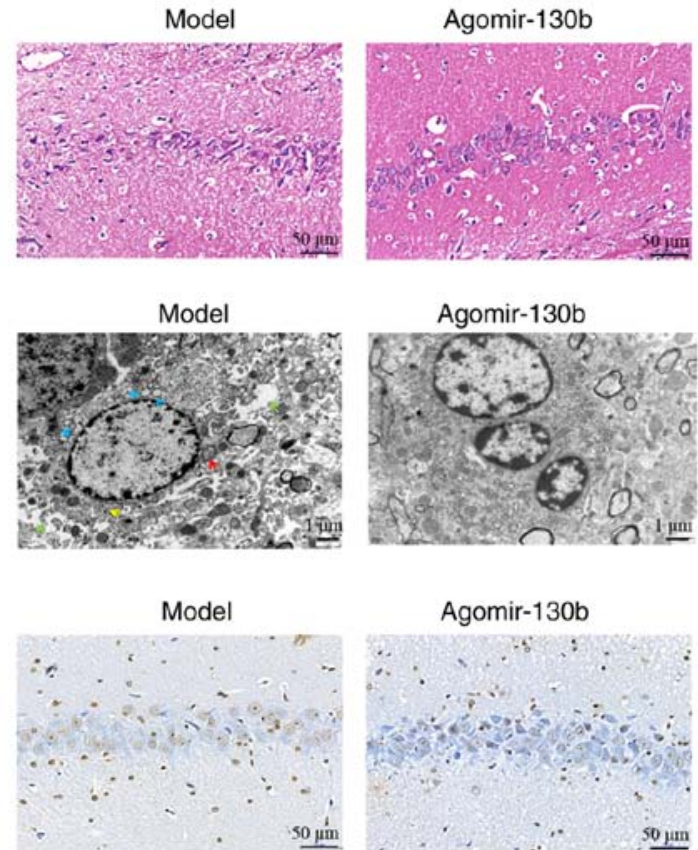

Agomir-130b

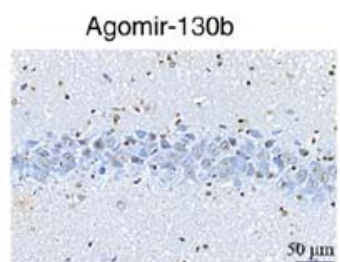

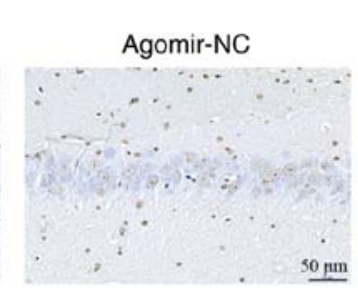
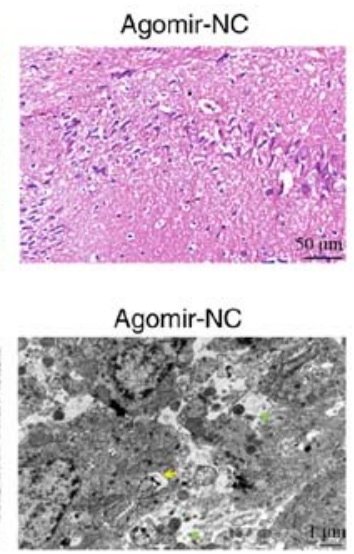

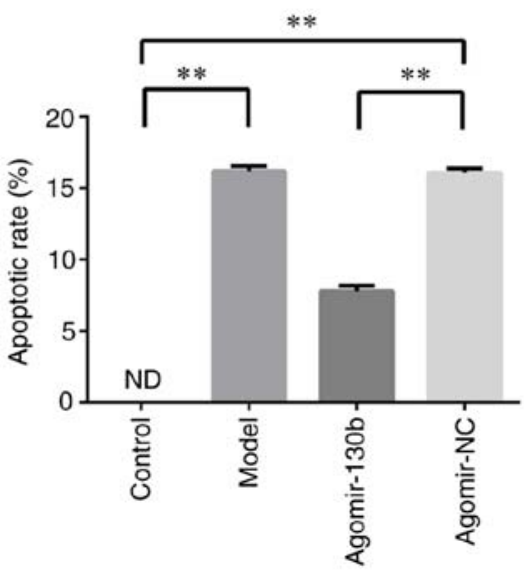

Figure 8. Effects of microRNA-130b on the damage of hippocampus neurons in rats with diabetic encephalopathy. (A) Images of hippocampus following hematoxylin and eosin staining. (B) Images of hippocampus ultrastructure obtained by transmission electron microscopy. Mitochondrial swelling (red arrows); rough endoplasmic reticulum dilatation (blue arrows); autophagy (yellow arrows); damaged synaptic structure (green arrows). (C) Images of hippocampus following TUNEL staining. ${ }^{* * *} \mathrm{P}<0.01$.

of the agomir-NC group, the ratios of Bax/Bcl-2 and cleaved caspase-3/caspase-3 were decreased in the agomir-130b group $(\mathrm{P}<0.01$ or $\mathrm{P}<0.05$, respectively; Fig. 10D and E). These results demonstrated that miR-130b regulated PTEN expression to activate Akt and inhibit the mitochondria-mediated apoptosis pathway in vivo.

\section{Discussion}

$\mathrm{DE}$ is a chronic complication of diabetes mellitus that damages the central nervous system and causes cognitive impairment (29). A high glucose environment can lead to the accumulation of advanced glycation end products, which can induce oxidative stress and subsequent damage to hippocampal neurons (30). The present study aimed to examine the effects of miR-130b on oxidative stress injury in rats with DE. The present data demonstrated that miR-130b could activate Akt by inhibiting PTEN, thereby improving oxidative stress damage in rats with DE.
Previous studies have demonstrated that miR-130b is an oncogene, which has been found to promote cancer cell proliferation, invasion and metastasis in hepatocellular carcinoma (31), breast cancer (32), gastric cancer (33), esophageal cancer (16) and glioma (34). A previous study found that miR-130b reduced fat deposition in C57BL/6 mice, reversed glucose tolerance and improved high-fat diet-induced obesity (35). In addition, miR-130b has been shown to attenuate kidney fibrosis and damage induced by diabetes (36). The results of the present study indicated that the expression level of miR-130b was reduced in PC12 and hippocampal cells stimulated with high glucose. The overexpression of miR-130b reduced the high glucose-induced apoptosis of PC12 and hippocampal cells, and improved cell viability, while miR-130b inhibitor increased apoptosis and reduced cell viability.

PTEN is the target gene of miR-130b in various cancer cells, and miR-130b promotes the development of cancer by regulating the expression of PTEN (14,37-39). PTEN can inhibit 

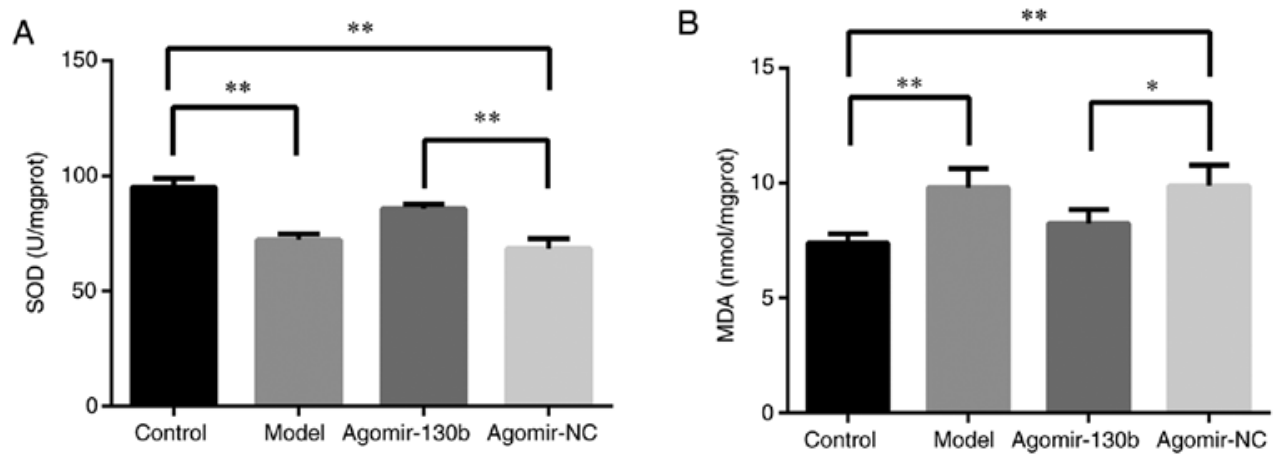

Figure 9. Effect of microRNA-130b on the activity of SOD and content of MDA in the hippocampus of rats in each group. (A) SOD activity and (B) MDA content in each group. The results are presented as the mean \pm standard deviation. ${ }^{*} \mathrm{P}<0.05,{ }^{* *} \mathrm{P}<0.01$. SOD, superoxide dismutase; MDA, malondialdehyde.
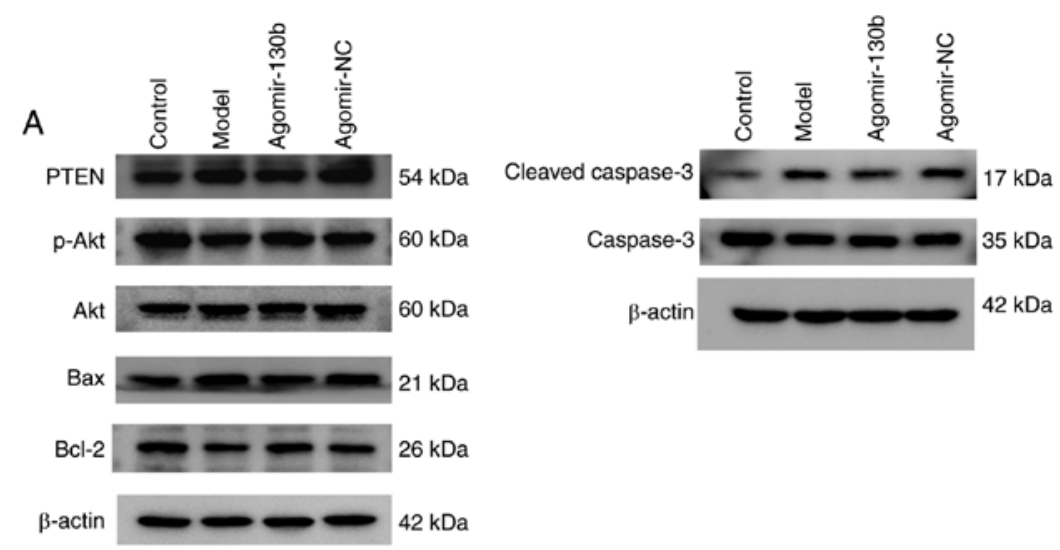

B
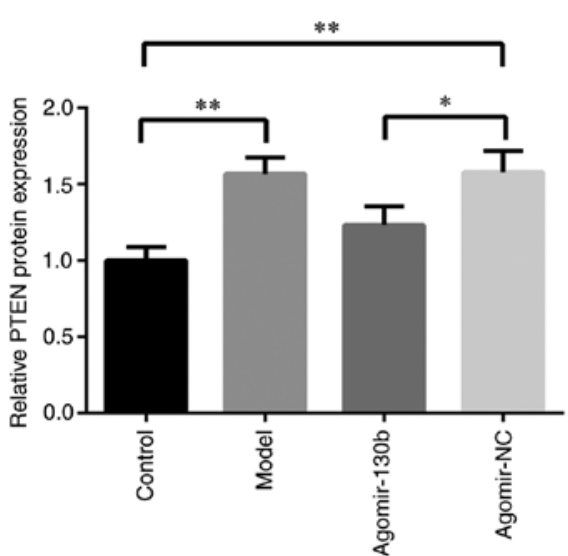

D

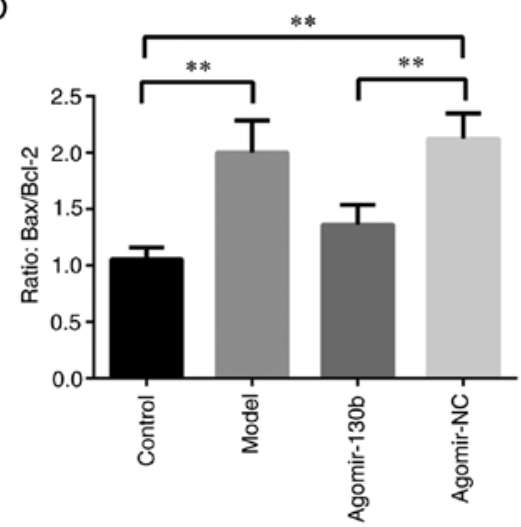

C

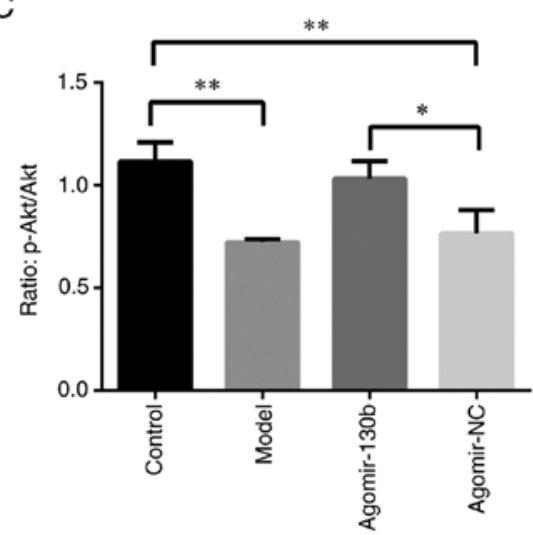

E

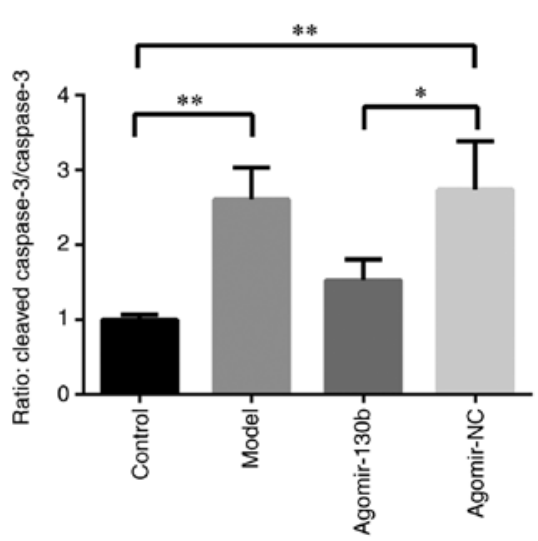

Figure 10. Effect of the microRNA-130b/PTEN axis on Akt activation and apoptosis-related protein levels in vivo. (A) Protein expression in the hippocampus was evaluated by western blot analysis. (B) Relative expression of PTEN in each group. (C) Activation of Akt, shown as the relative intensity of phosphorylated-Akt to Akt. (D) Activation of apoptosis, shown as the relative intensity ratio of Bax to Bcl-2. (E) Relative intensity ratio of cleaved caspase-3 to caspase-3 in each group. Data were acquired from three independent experiments. The results are presented as the mean \pm standard deviation. " $\mathrm{P}<0.05$, ${ }^{* *} \mathrm{P}<0.01$. PTEN, phosphatase and tensin homolog. 
the PI3K/Akt signaling pathway, which can attenuate oxidative stress-induced damage by activating downstream antioxidant proteins (40). Therefore, it was hypothesized that miR-130b could attenuate high glucose-induced oxidative stress damage by inhibiting PTEN and activating Akt. SOD is an antioxidant enzyme involved in free radical scavenging, while MDA is a product of lipid peroxidation, and its content can reflect the level of free radicals. These two indicators are commonly used to assess the level of oxidative stress (41). The present study also confirmed that PTEN is the target gene of miR-130b, and showed that PTEN was involved in the high glucose-induced oxidative stress injuries of PC12 and hippocampal cells. The downregulation of the expression of PTEN may improve cell viability and inhibit cell apoptosis by increasing SOD activity and reducing MDA content, indicating that miR-130b can regulate PTEN to ameliorate oxidative stress-related cell injury.

When cells are subjected to oxidative stress, the metabolic and functional characteristics of mitochondria change, and the intrinsic apoptotic pathway mediated by mitochondria is initiated (42). The Bcl-2 family is a key regulatory protein family in the mitochondrial apoptosis pathway. This family includes the anti-apoptotic protein, $\mathrm{Bcl}-2$, and the pro-apoptotic protein, Bax. The $\mathrm{Bax} / \mathrm{Bcl}-2$ ratio has been used as a marker to represent the effect of apoptosis (43). Caspase-3 is one of the members of the caspase protein family that mediates apoptosis. Caspase-3 is cleaved into cleaved caspase-3 and then activated to cause apoptosis (44). The data of the present study demonstrated that miR-130b regulated PTEN to increase the p-Akt/Akt ratio, and reduce the $\mathrm{Bax} / \mathrm{Bcl}-2$ and the cleaved caspase-3/caspase- 3 ratios in $\mathrm{PC} 12$ cells hippocampal cells, suggesting that miR-130b could prevent cell apoptosis.

The present study established a rat model of DE to further evaluate the effects of miR-130b. The expression level of miR-130b was downregulated in the hippocampal tissue of rats with $\mathrm{DE}$, and the overexpression of miR-130b attenuated cognitive impairment and hippocampal damage in DE model rats. The overexpression of miR-130b in vivo increased SOD activity and the p-Akt/Akt ratio, and reduced cell apoptosis, the MDA content, the ratio of Bax to Bcl-2 and the expression of cleaved caspase- 3 in the hippocampus of rats with DE. This suggests that miR-130b may attenuate cognitive impairment by protecting the hippocampus from oxidative stress-induced damage in rats with DE.

In conclusion, the results of the present study demonstrated that miR-130b improved oxidative stress-induced injury in rats with DE and in high glucose-induced PC12 and hippocampal cells by inhibiting PTEN and activating the PI3K/Akt pathway. The role of PTEN in DE remains unclear. Further research is thus required to focus on the role of PTEN in DE and other cognitive disorders. In addition, the present study only partially discussed the role of PTEN as a target gene of miR-130b in the treatment of DE. However, miR-130b may also target other genes to protect nerve cells, which warrants investigation in future studies.

\section{Acknowledgements}

Not applicable.

\section{Funding}

The present study was supported by the Natural Science Foundation of China (grant no. 81372617).

\section{Availability of data and materials}

The datasets used or analyzed during the current study are available from the corresponding author on reasonable request.

\section{Authors' contributions}

YL, MY, HL and JL designed and performed the experiments. MY and RX collected and analyzed the data. YL wrote the manuscript. HL, RX and JL assisted in the drafting of the manuscript. YL, RX and MY confirm the authenticity of all the raw data. All authors have read and approved the final manuscript.

\section{Ethics approval and consent to participate}

The study protocol was approved by the Animal Experimental Ethics Committee of Henan Provincial People's Hospital (approval no. 2020408A).

\section{Patient consent for publication}

Not applicable.

\section{Competing interests}

The authors declare that they have no competing interests.

\section{References}

1. Sima AA and Li ZG: The effect of C-peptide on cognitive dysfunction and hippocampal apoptosis in type 1 diabetic rats. Diabetes 54: 1497-1505, 2005.

2. Tirassa P, Maccarone M, Florenzano F, Cartolano S and De Nicolò S: Vascular and neuronal protection induced by the ocular administration of nerve growth factor in diabetic-induced rat encephalopathy. CNS Neurosci Ther 19: 307-318, 2013.

3. Samarghandian S, Azimi-Nezhad M and Samini F: Ameliorative effect of saffron aqueous extract on hyperglycemia, hyperlipidemia, and oxidative stress on diabetic encephalopathy in streptozotocin induced experimental diabetes mellitus. Biomed Res Int 2014: 920857, 2014.

4. Reinhard H, Garde E, Skimminge A, Åkeson P, Ramsøy TZ, Winther K, Parving HH, Rossing P and Jacobsen PK: Plasma NT-proBNP and white matter hyperintensities in type 2 diabetic patients. Cardiovasc Diabetol 11: 119, 2012.

5. Sima AA: Encephalopathies: The emerging diabetic complications. Acta Diabetol 47: 279-293, 2010.

6. Shi B, Wang Y, Zhao R, Long X, Deng W and Wang Z: Bone marrow mesenchymal stem cell-derived exosomal miR-21 protects C-kit+ cardiac stem cells from oxidative injury through the PTEN/PI3K/Akt axis. PLoS One 13: e0191616, 2018.

7. Nandi SS, Zheng H, Sharma NM, Shahshahan HR, Patel KP and Mishra PK: Lack of miR-133a decreases contractility of diabetic hearts: A role for novel cross talk between tyrosine aminotransferase and tyrosine hydroxylase. Diabetes 65: 3075-3090, 2016.

8. Kölling M, Kaucsar T, Schauerte C, Hübner A, Dettling A, Park JK, Busch M, Wulff X, Meier M, Scherf K, et al: Therapeutic miR-21 silencing ameliorates diabetic kidney disease in mice. Mol Ther 25: 165-180, 2017.

9. Zhang Y, Song C, Liu J, Bi Y and Li H: Inhibition of miR-25 aggravates diabetic peripheral neuropathy. Neuroreport 29: 945-953, 2018. 
10. Sun Z, Ma Y, Chen F, Wang S, Chen B and Shi J: miR-133b and miR-199b knockdown attenuate TGF- $\beta 1$-induced epithelial to mesenchymal transition and renal fibrosis by targeting SIRT1 in diabetic nephropathy. Eur J Pharmacol 837: 96-104, 2018.

11. Bai X, Geng J, Zhou Z, Tian J and Li X: MicroRNA-130b improves renal tubulointerstitial fibrosis via repression of Snail-induced epithelial-mesenchymal transition in diabetic nephropathy. Sci Rep 6: 20475, 2016.

12. Lv C, Zhou YH, Wu C, Shao Y, Lu CL and Wang QY: The changes in miR-130b levels in human serum and the correlation with the severity of diabetic nephropathy. Diabetes Metab Res Rev 31: 717-724, 2015

13. Yuan Y, Peng W, Liu Y and Xu Z: Circulating miR-130 and its target PPAR- $\gamma$ may be potential biomarkers in patients of coronary artery disease with type 2 diabetes mellitus. Mol Genet Genomic Med 7: e909, 2019.

14. Sekino Y, Sakamoto N, Sentani K, Oue N, Teishima J, Matsubara A and Yasui W: miR-130b promotes sunitinib resistance through regulation of PTEN in renal cell carcinoma. Oncology 97: 164-172, 2019.

15. Yuan B, Zou M, Zhao Y, Zhang K, Sun Y and Peng X: Upregulation of miR-130b-3p activates the PTEN/PI3K/AKT/ $\mathrm{NF}-\kappa \mathrm{B}$ pathway to defense against mycoplasma gallisepticum (HS strain) infection of chicken. Int J Mol Sci 19: 2172, 2018

16. Yu T, Cao R, Li S, Fu M, Ren L, Chen W, Zhu H, Zhan Q and Shi R: MiR-130b plays an oncogenic role by repressing PTEN expression in esophageal squamous cell carcinoma cells. BMC Cancer 15: 29, 2015.

17. Ciuffreda L, Falcone I, Incani UC, Del Curatolo A, Conciatori F, Matteoni S, Vari S, Vaccaro V, Cognetti F and Milella M: PTEN expression and function in adult cancer stem cells and prospects for therapeutic targeting. Adv Biol Regul 56: 66-80, 2014

18. Worby CA and Dixon JE: PTEN. Annu Rev Biochem 83: 641-669, 2014.

19. Pompura SL and Dominguez-Villar M: The PI3K/AKT signaling pathway in regulatory T-cell development, stability, and function. J Leukoc Biol, Jan 22, 2018 (Online ahead of print).

20. Wang M, Hu R, Wang Y, Liu L, You H, Zhang J, Wu X, Pei T, Wang F, Lu L, et al: Atractylenolide III attenuates muscle wasting in chronic kidney disease via the oxidative stress-mediated PI3K/AKT/mTOR pathway. Oxid Med Cell Longev 2019: 1875471,2019

21. Zhang B, Zhao Z, Meng X, Chen H, Fu G and Xie K: Hydrogen ameliorates oxidative stress via PI3K-Akt signaling pathway in UVB-induced HaCaT cells. Int J Mol Med 41: 3653-3661, 2018.

22. Wen Z, Hou W, Wu W, Zhao Y, Dong X, Bai X, Peng L and Song L: 6'-O-galloylpaeoniflorin attenuates cerebral ischemia reperfusion-induced neuroinflammation and oxidative stress via PI3K/Akt/Nrf2 activation. Oxid Med Cell Longev 2018 8678267,2018

23. Mohamed AK, Bierhaus A, Schiekofer S, Tritschler H, Ziegler R and Nawroth PP: The role of oxidative stress and NF-kappaB activation in late diabetic complications. Biofactors 10: 157-167, 1999

24. Chen M, Zheng H, Wei T, Wang D, Xia H, Zhao L, Ji J and Gao H: High glucose-induced PC12 cell death by increasing glutamate production and decreasing methyl group metabolism. Biomed Res Int 2016: 4125731, 2016.

25. Mai H, Fan W, Wang Y, Cai Y, Li X, Chen F, Chen X, Yang J, Tang $\mathrm{P}$, Chen $\mathrm{H}$, et al: Intranasal administration of miR-146a agomir rescued the pathological process and cognitive impairment in an AD mouse model. Mol Ther Nucleic Acids 18: 681-695, 2019.

26. Livak KJ and Schmittgen TD: Analysis of relative gene expression data using real-time quantitative PCR and the 2(-Delta Delta C(T)) method. Methods 25: 402-408, 2001.

27. Kameyama T, Nabeshima T and Kozawa T: Step-down-type passive avoidance- and escape-learning method. Suitability for experimental amnesia models. J Pharmacol Methods 16: 39-52, 1986.

28. Luo Y, Kuang S, Xue L and Yang J: The mechanism of 5 -lipoxygenase in the impairment of learning and memory in rats subjected to chronic unpredictable mild stress. Physiol Behav 167: 145-153, 2016.
29. Díaz-Gerevini GT, Daín A, Pasqualini ME, López CB Eynard AR and Repossi G: Diabetic encephalopathy: Beneficial effects of supplementation with fatty acids $\omega 3$ and nordihydroguaiaretic acid in a spontaneous diabetes rat model. Lipids Health Dis 18: 43, 2019.

30. Yaffe K, Lindquist K, Schwartz AV, Vitartas C, Vittinghoff E, Satterfield S, Simonsick EM, Launer L, Rosano C, Cauley JA and Harris T: Advanced glycation end product level, diabetes, and accelerated cognitive aging. Neurology 77: 1351-1356, 2011.

31. Tu K, Zheng X, Dou C, Li C, Yang W, Yao Y and Liu Q: MicroRNA-130b promotes cell aggressiveness by inhibiting peroxisome proliferator-activated receptor gamma in human hepatocellular carcinoma. Int J Mol Sci 15: 20486-20499, 2014.

32. Miao Y, Zheng W, Li N, Su Z, Zhao L, Zhou H and Jia L: MicroRNA-130b targets PTEN to mediate drug resistance and proliferation of breast cancer cells via the PI3K/Akt signaling pathway. Sci Rep 7: 41942, 2017.

33. Lai KW, Koh KX, Loh M, Tada K, Subramaniam MM, Lim XY, Vaithilingam A, Salto-Tellez M, Iacopetta B, Ito Y, et al: MicroRNA-130b regulates the tumour suppressor RUNX3 in gastric cancer. Eur J Cancer 46: 1456-1463, 2010.

34. Tong L, Chu M, Yan B, Zhao W, Liu S, Wei W, Lou H, Zhang S, Ma S, Xu J and Wei L: MTDH promotes glioma invasion through regulating miR-130b-ceRNAs. Oncotarget 8: 17738-17749, 2017.

35. Pan S, Yang X, Jia Y, Li Y, Chen R, Wang M, Cai D and Zhao R: Intravenous injection of microvesicle-delivery miR-130b alleviates high-fat diet-induced obesity in C57BL/6 mice through translational repression of PPAR- $\gamma$. J Biomed Sci 22: 86, 2015

36. Liu Y, Yang Y, Wang Q, Kahaer A, Zhang J, Liao J, Abudureyimu M, Yahefu R, Qi J, Zhao L and Zhu J: Regulatory effect of $1,25(\mathrm{OH}) 2 \mathrm{D} 3$ on TGF- $\beta 1$ and miR-130b expression in streptozotocin-induced diabetic nephropathy in rats. Int J Endocrinol 2019: 1231346, 2019.

37. Zhang Q, Zhang B, Sun L, Yan Q, Zhang Y, Zhang Z, Su Y and Wang C: MicroRNA-130b targets PTEN to induce resistance to cisplatin in lung cancer cells by activating $\mathrm{Wnt} / \beta$-catenin pathway. Cell Biochem Funct 36: 194-202, 2018.

38. Chang RM, Xu JF, Fang F, Yang H and Yang LY: MicroRNA-130b promotes proliferation and EMT-induced metastasis via PTEN/ p-AKT/HIF-1 $\alpha$ signaling. Tumour Biol 37: 10609-10619, 2016.

39. Egawa H, Jingushi K, Hirono T, Ueda Y, Kitae K, Nakata W, Fujita K, Uemura M, Nonomura N and Tsujikawa K: The miR-130 family promotes cell migration and invasion in bladder cancer through FAK and Akt phosphorylation by regulating PTEN. Sci Rep 6: 20574, 2016.

40. Lee YJ, Jeong HY, Kim YB, Lee YJ, Won SY, Shim JH, Cho MK, Nam HS and Lee SH: Reactive oxygen species and PI3K/Akt signaling play key roles in the induction of Nrf2-driven heme oxygenase-1 expression in sulforaphane-treated human mesothelioma MSTO-211H cells. Food Chem Toxicol 50: 116-123, 2012

41. Wang Y, Wang Q, Li J, Lu G and Liu Z: Glutamine improves oxidative stress through the Wnt $3 \mathrm{a} / \beta$-catenin signaling pathway in Alzheimer's disease in vitro and in vivo. Biomed Res Int 2019: 4690280, 2019.

42. Askari H, Rajani SF, Poorebrahim M, Haghi-Aminjan H, Raeis-Abdollahi $\mathrm{E}$ and Abdollahi M: A glance at the therapeutic potential of irisin against diseases involving inflammation, oxidative stress, and apoptosis: An introductory review. Pharmacol Res 129: 44-55, 2018.

43. Del Principe MI, Dal Bo M, Bittolo T, Buccisano F, Rossi FM, Zucchetto A, Rossi D, Bomben R, Maurillo L, Cefalo M, et al: Clinical significance of bax/bcl-2 ratio in chronic lymphocytic leukemia. Haematologica 101: 77-85, 2016.

44. Li H, Yin A, Cheng Z, Feng M, Zhang H, Xu J, Wang F and Qian L: Attenuation of Na/K-ATPase/Src/ROS amplification signal pathway with pNaktide ameliorates myocardial ischemia-reperfusion injury. Int J Biol Macromol 118: 1142-1148, 2018.

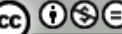

This work is licensed under a Creative Commons Attribution-NonCommercial-NoDerivatives 4.0 International (CC BY-NC-ND 4.0) License. 